\title{
Visual arts and genetics: lessons from the past
}

\author{
Art, Sex and Eugenics: Corpus Delecti \\ Visual Arts and Genetics: Lessons from the past \\ Edited by Fae Brauer (Author) and Anthea Callen \\ ISBN-10: 0754658279; ISBN-13: 978-0754658276 \\ Published by: Ashgate \\ Price: $£ 65.00$ \\ .........
}

Nicola Marziliano

European Journal of Human Genetics (2011) 19, 122; doi:10.1038/ejhg.2010.155

$\mathrm{N}$ o doubt our contemporary age is dominated by images. Moreover, beauty and appearance are a must in Western society. This book is an extremely elegant, multicultural and multidisciplinary voyage into the roots of 'distortion' that led the desire of a fit and beautiful body, which always accompanied the human spirit (irrespective of the culture to which one belonged), to the promulgation in 1934 of the Eugenic Sterilization Law from the Third Reich: 250000 people diagnosed with alcoholism, manic depression, schizophrenia, hereditary epilepsy, blindness and deafness, congenital mental deficiency, hereditary disease and physical deformity disrupting locomotion were sterilized. This was the first step in a complex and systemic eugenic campaign culminating in the extermination of Jews, homosexuals, gypsies, political dissidents and others classified as physiologically or psychologically 'degenerate'.

The concept behind the three words 'Art, Sex and Eugenics' is made available thoroughly in the eight chapters of this book.

Art (or better visual art) was of great support in the Nazi eugenic campaign. Through films, posters, leaflets and carefully staged photographs, Jewish people and people of colour were inscribed as diseased and deformed, as well as morally and culturally degenerate. However, not only was such culture present in the Third Reich (ie, let us think of the artworks celebrating sports at the 1936 Olympic Games) but it was also alive and well in the Popular Front France: Léon Blum's Socialist government that reputedly stood against Fascism. Such artworks indeed had an integral role in popularizing French eugenics and desiring a eugenics body. The different ways in which the body became inscribed as the prime site of delectation through the interplay between art and visual cultures, modern medicine, science, anatomy, anthropology, anthropometry, criminology and eugenics in North America, in the French Third Republic, Victorian and interwar Britain, the Weimar Republic and Nazi Germany, the Soviet Union, Australia and New Zealand are examined in each chapter of this book. In aestheticizing health, art was able to inscribe fitness as natural, evolved, civilized and beautiful.

Sex and eugenics have been historically positioned as an oxymoron. The very term eugenics signifies control of sexuality in terms of its rationalization or strict management to ensure that nothing is wasted away in securing the betterment of a society, race or nation. By contrast, the word sex conjures up an action so excessive and uncontrollable by nature that it is capable of corrupting and contaminating an entire national order. Sex beyond imperative procreation was called 'excessive' and 'unnatural'. Constantly, warnings were issued about its destruction of energy and ambition, its weakening of virility and potency and its contamination of thousands. Through nudity and provocative posing, aspirational imagery made it seem normal and natural to desire to have sexual contact with the delectable body for 'rational procreation'. Conversely, the abject image was designed to evoke repulsion: aversion to emulation of and sexual contact with the degenerate body compounded its alignment with syphilis and other forms of sexual contagion.

To summarize the content of the eight chapters, first is the 'measurement of man' and the 'ranking of race', particularly once the ideal body was established through canonization of the statues Apollo Belvedere (Leochares, $350 \mathrm{BC}$; frontispiece image) and Gladiateur Bourgeois (Denis Diderot and Jean le Rond d'Alambert, 1770; Figure 4.2). Second is the mapping of the body through anthropometry, craniometry and metric photography and through ways in which these microscopes of conduct inscribed normality and beauty upon the fit body, as well as degeneracy upon the body as a result of alcohol, criminal activities, prostitution, syphilis or colour and upon Modernist art. Third is the function of eugenics as a scientia sexualis through the scripting of sex and the roles of art and visual cultures in making the eugenic body appear delectable. Fourth is the role of nakedness in body cultures and fine art. Fifth is the stripping of race. Sixth is the posing of the eugenic body to incite exhibitionism and voyeurism. Seventh is the idealization of the naked male with body to arouse emulation and heterosexual association, as well as homosociality and homoeroticism. The last and eighth chapter is on the representation of woman as a titillating eugenic body to signal her ripeness for procreative sex and nurturance of a new race.

We congratulate the two editors, Fae Brauer and Anthea Callen, on the enormous effort of smoothly pooling together the different perspectives that arose from the contributors, among others, of a controversial topic that is always up-to-date, such as eugenics and its corollary implications

Dr Nicola Marziliano is at the Molecular Pathology Laboratory, Azienda Ospedaliera Ospedale Maggiore Cà Granda Niguarda, Piazzale Golgi 2, Milan-IT, Italy. Tel and Fax: +390264444696; E-mail: Nicola.marziliano@ ospedaleniguarda.it,

http://:www.ospedaleniguarda.it 